\title{
Phospholipid film in electrolyte-gated organic field-effect transistors
}

\author{
Serafina Cotrone, Marianna Ambrico, Henrik Toss, M. Daniela Angione, Maria Magliulo, \\ Antonia Mallardi, Magnus Berggren, Gerardo Palazzo, Gilles Horowitz, \\ Teresa Ligonzo and Luisa Torsi
}

\section{Linköping University Post Print}

\begin{abstract}
N.B.: When citing this work, cite the original article.
\end{abstract}
Original Publication:

Serafina Cotrone, Marianna Ambrico, Henrik Toss, M. Daniela Angione, Maria Magliulo, Antonia Mallardi, Magnus Berggren, Gerardo Palazzo, Gilles Horowitz, Teresa Ligonzo and Luisa Torsi, Phospholipid film in electrolyte-gated organic field-effect transistors, 2012, Organic electronics, (13), 4, 638-644.

http://dx.doi.org/10.1016/j.orgel.2012.01.002

Copyright: Elsevier http://www.elsevier.com/

Postprint available at: Linköping University Electronic Press http://urn.kb.se/resolve?urn=urn:nbn:se:liu:diva-74742 


\section{Phospholipid film in electrolyte-gated organic field-effect transistors}

Serafina Cotrone ${ }^{1}$, MariannaAmbrico ${ }^{2}$, Henrik Toss ${ }^{3}$, M. Daniela Angione ${ }^{1}$, Maria Magliulo ${ }^{1}$, Antonia Mallardi ${ }^{4}$, Magnus Berggren ${ }^{3}$, Gerardo Palazzo ${ }^{1}$, Gilles Horowitz ${ }^{5}$, Teresa Ligonzo ${ }^{6} *$ and Luisa Torsi ${ }^{1} *$

*Corresponding authors: E-mail address torsi@chimica.uniba.it ligonzo@ba.infn.it

${ }^{1}$ Dipartimento di Chimica, Università di Bari “Aldo Moro”, Via Orabona 4, 70126, Bari (Italy)

${ }^{2}$ CNR-IMIP, Sezione Territoriale di Bari, Via Orabona4, 70126, Bari (Italy)

${ }^{3}$ Organic Electronics, ITN Linköping University, SE-601 74 Norrköping (Sweden)

${ }^{4}$ CNR-IPCF, Istituto per i Processi Chimico-Fisici Via Orabona 4, 70126, Bari (Italy)

${ }^{5}$ ITODYS, University Paris Diderot15 rue Jean-Antoine de Ba1 “f, 75205 Paris cedex 13 (France)

${ }^{6}$ Dipartimento di Fisica, Università di Bari “Aldo Moro” Via Amendola 172, 70126, Bari (Italy)

Keywords: electrolyte-gated field-effect transistors, phospholipid layers, poly-3-hexylthiophene (P3HT), Electrochemical Impedance Spectroscopy

\section{Abstract}

A totally innovative electrolyte-gated field effect transistor, embedding a phospholipid film at the interface between the organic semiconductor and the gating solution, is described. The electronic properties of OFETs including a phospholipid film are studied in both pure water and in an electrolyte solution and compared to those of an OFET with the organic semiconductor directly in contact with the gating solution. In addition, to investigate the role of the lipid layers in the charge polarization process and quantify the field-effect mobility, impedance spectroscopy was employed. The results indicate that the integration of the biological film minimizes the penetration of ions into the organic semiconductor thus leading to a capacitive operational mode as opposed to an electrochemical one. The OFETs operate at low voltages with a field-effect mobility in the $10^{-3} \mathrm{~cm}^{2} \mathrm{~V}^{-1} \mathrm{~s}^{-1}$ range and an on/off current ratio of $10^{3}$. This achievement opens perspectives to the development of FET biosensors potentially capable to operate in direct contact with physiological fluids. 


\section{Introduction}

Numerous investigations have been driven on supported or tethered lipid bilayers because these systems, which can self-assemble due to their amphiphilic nature, provide a natural environment to membrane proteins immobilization [1]. To date, lipid bilayers [2] also including ion-channels [3], have been implemented in a field-effect transistor (FET) structure for $\mathrm{pH}$ and ionic detection in general. The binding of a protein to a lipid monolayer or bilayer surface has been investigated too [4]. The lipid layer is usually deposited on the surface of the FET electronic active layer, which in the elicited cases is a nanostructured system constituted of carbon nanotubes or silicon nanowires. Despite the attractive features offered by such nano-devices, their fabrication can present cost and scalability issues.

Interfacing supported lipid layers to an organic field-effect transistor (OFET) can offer the advantage of a low-cost and high-throughput fabrication procedure. Besides, OFET sensors have been shown to operate as multi-parameter devices and to deliver an amplified response $[5,6]$. Among organic transistor devices, interesting are the electrochemically gated OFET [7] which are capable to operate in water in the sub-volt regime. The gating is achieved in water by means of ion channels embedded into a lipid bilayer membrane interfaced to the organic semiconductor (OS) [8]. The application of a proper gate bias can trigger the opening of the ion-channels, thus allowing cations to migrate into the p-type OS and contributing to enhance the source-drain current whose amplification is therefore largely not capacitively driven [7]. Although the concept is interesting and can be used for many bio-electronic applications [9], the inherent doping occurring when ions enter the OS can cause the electronic properties to degrade, which is further supported by the appearance of an hysteretic behavior in the currentvoltage (I-V) characteristics $[10,11]$. To minimize the doping effect, a gating through a polymeric electrolyte composed of large poly-anionic chains was proposed [10]. A capacitive 
coupling between the polymeric electrolyte and the OS is generated in this case by the formation of a Helmholtz double layer [12-13] yielding a capacitance of $10 \mu \mathrm{F}^{*} \mathrm{~cm}^{-2}$ [10]. A Helmholtz double layer can also be generated in a water-gated OFET [14-15] when pure water is directly interfaced to the OS. These devices have been shown to operate in a mostly capacitive mode thus demonstrating that no significant organic semiconductor degradation occurs under water operation. Water-gated FETs, like electrochemical ones, can be operated in the sub-volt regime and exhibit a mobility ranging between $10^{-3} \mathrm{~cm}^{2} \mathrm{~V}^{-1} \mathrm{~s}^{-1}[14]$ and $10^{-1} \mathrm{~cm}^{2}$ $\mathrm{V}^{-1} \mathrm{~s}^{-1}$ if a semiconductor/insulator blend is used as active layer [15].

The present study deals with an electrolyte gated OFET in which a phospholipid film was introduced at the interface between the OS and the gating solution to minimize electrochemical doping of the organic semiconductor. The rationale for implementing such a device structure relies on the known property of phospholipid (PL) membranes (particularly zwitterionic ones, vide infra) to act as a barrier against ionic species migration. This can lead in principle to a purely capacitive gating as opposed to an electrochemical operation. The electronic properties of electrolyte-gated OFET including a phospholipid film (PL-OFET) are studied by measuring the Current-Voltage (I-V) characteristic and by means of Electrochemical Impedance Spectroscopy (EIS) and compared to those of OFETs having the OS directly coupled with the gating solution. All the measurements were performed in both pure water and in an electrolyte solution at physiologically relevant concentrations.

\section{Material and methods}

\subsection{Lipid vesicles preparation}

Lipid vesicles suspension was prepared by dissolving $10 \mathrm{mg}$ of soy bean lecithin (EPIKURON 200 from Cargill) in chloroform. The solvent was then evaporated under a flow of nitrogen. In order to remove all traces of organic solvent, the lipid film was kept under vacuum for $60 \mathrm{~min}$. Lipids were rehydrated in $1 \mathrm{~mL}$ of distilled water and sonicated on ice for 
10 min. The obtained multilamellar vesicles suspension was repeatedly subjected to extrusion through a polycarbonate filter having pore sizes of $100 \mathrm{~nm}$ using the Avanti mini-extruder (Avanti Polar), to obtain small unilamellar vesicles. Such a preparation was carried just before the PL spin coating described in the following. It is worth of note that the PLs are stable against oxidation and hydrolysis over time window of months [16] (i.e. a time scale very long compared to that encompassed by the experiments here proposed).

\subsection{OFET fabrication}

The transistors have a top-gate, bottom contact configuration. The substrate consisted of a silicon wafer with thermally grown silicon dioxide onto which gold source (S) and drain (D) contacts were defined by a photolithographic procedure with a channel length and width of $10 \mu \mathrm{m}$ and $30000 \mu \mathrm{m}$, respectively. Poly-3-hexylthiophene (P3HT) was purchased to BASF (RR>98\%, SepiolidP200) and used after a purification treatmentconsisting of successive Soxhlet extractions with methanol and exane [17]. It was dissolved in chloroform at a concentration of $2.6 \mathrm{mg} \mathrm{mL}^{-1}$ and spin coated on the electrodes at $2000 \mathrm{rpm}$ for 30sec. Finally, to obtain PL layers, $2 \mu \mathrm{L}$ of lipid vesicles suspended in water were spin coated directly onto the P3HT surface at low speed (150 rpm for $10 \mathrm{~min})$. A water (HPLC grade) or a $\mathrm{LiClO}_{4}$ solution $(0.005 \mathrm{M})$ droplet was generated with a calibrated micro syringe and deposited onto the organic semiconductor surface. A gold plate in contact with the liquid solution served as the gate electrode.

\subsection{Electrical measurements}

The I-V curves were measured with a semiconductor parameter analyzer (Agilent 4155C). To prevent the water droplet from drying, a humid environment was maintained around the devices during the measurements. Three transistors of each type were tested. The field-effect mobility, threshold voltage and on/off ratio, are given as averaged values on eight measurements on the same transistor, as extracted from the transfer characteristics [18] in the saturation regime. 


\subsection{Impedance measurements}

EIS measurements were carried out on two kinds of structures. The first one consisted of the sole P3HT and the gating solution (a water or a lithium perchlorate solution droplet) placed between two gold electrodes, while in the second one, a phospholipid layer is deposited on the P3HT surface. The impedance measurements were performed with an Alpha high-resolution dielectric analyzer (Novacontrol $\mathrm{GmbH})$. The impedance $(\mathrm{Z})$ spectra were recorded in the $0.1 \mathrm{~Hz}$ to $1 \mathrm{MHz}$ frequency range by applying a $\mathrm{V}_{\mathrm{AC}}=50 \mathrm{mV}$ sine-wave voltage signal pertubation. A continuous bias of $0.0 \mathrm{~V}$ and $-0.6 \mathrm{~V}$ was superposed to the AC signal. The data were plotted as imaginary vs. real part (-ImZ vs. ReZ) (Nyquist plot) and fitted with a free software package (EIS Spectrum analyser) able to model an equivalent electrical circuit.

\section{Results and discussion}

Fig.1 shows the structure of the PL-OFET along with the P3HT and the phosphatidylcholine PL molecular structures. These lipid molecules have a strong permanent dipole moment associated with the phosphate negative and the $\mathrm{N}^{+}\left(\mathrm{CH}_{3}\right)_{3}$ positive charges; conversely, the long hydrocarbon chains are highly hydrophobic. The presence of both these features on the same molecular scaffold confers to these PLs an amphiphilic (zwitterionic) character that allows them to self-assemble spontaneously, thus forming a structure composed of bilayers that leads to closed vesicles in water [19]. When aqueous suspensions of these PL vesicles are allowed to dry, they form stakes of bilayers, which is supported by the small angle X-ray scattering curve shown in the Supplementary information (Fig. 1SI) where the lamellar periodicity can be observed. Moreover, the repeat distance extracted from the position of the first-order Bragg's peak is $5 \mathrm{~nm}$, that is, twice the size of a phospholipid molecule, thus demonstrating that the bilayer is the repeated structure. Preliminary X-ray photoelectron spectroscopy measurements carried out on a structure composed of a PL film deposited on the OS, brings evidence for an in-plane homogeneity of the biological layer having a thickness 
higher than $10 \mathrm{~nm}$. This means that more than two bilayers are formed on the surface of the organic semiconductor (data not shown). In this study, the PL-OFET is either interfaced to pure water or to an aqueous $0.005 \mathrm{M}$ lithium-perchlorate solution $\left(\mathrm{LiClO}_{4}\right)$. We note that previous studies have shown how a direct exposure of the $\mathrm{OS}$ to a $\mathrm{LiClO}_{4}$ electrolyte results in doping and an associated OFET performance degradation [10, 11].

In Fig. 2A the source-drain current $\left(\mathrm{I}_{\mathrm{DS}}\right)$ - voltage $\left(\mathrm{V}_{\mathrm{DS}}\right)$ characteristic curves are reported for a water-gated PL-OFET at gate biases $\left(\mathrm{V}_{\mathrm{G}}\right)$, ranging between 0.1 and $-0.5 \mathrm{~V}$. The OFET operation under aqueous environment requires that the bias remains below the water electrolysis potential $(-0.8 \mathrm{~V})$. It is clear that the forward and backward potential sweeps do not support the occurrence of any current hysteresis thus indicating that the exposure to water during the biological layer deposition does not affect the P3HT electronic performances (for further details see Fig. 2SI). The PL-OFET figures of merit reported in Table 1, show an electronic performance comparable to those previously published for a water-gated OFET [14].

To investigate the role of the lipid film in the charge polarization process and to quantify the OFETs field-effect mobility $\left(\mu_{\mathrm{FET}}\right)$, the gate-dielectric capacitance of the OS and the OS-PL interfaces exposed to pure water were evaluated by means of impedance spectroscopy. To this aim, a structure comprising the OS and the gating solution (a water droplet) stacked between two gold electrodes $\left(\mathrm{Au} / \mathrm{P} 3 \mathrm{HT} / \mathrm{H}_{2} \mathrm{O} / \mathrm{Au}\right)$ was used. For the PL-OFET, a phospholipid film was deposited on the OS film and interfaced to water ( $\left.\mathrm{Au} / \mathrm{P} 3 \mathrm{HT} / \mathrm{PL} / \mathrm{H}_{2} \mathrm{O} / \mathrm{Au}\right)$. EIS was performed in the $0.1-10^{6} \mathrm{~Hz}$ range while capacitance values for $\mu_{\mathrm{FET}}$ estimation were taken at the lowest accessible frequency $(0.1 \mathrm{~Hz})$. The phase shift $\theta$ between the applied sine-wave (amplitude: $50 \mathrm{mV}$ and frequency: $0.1 \mathrm{~Hz} \div 1 \mathrm{MHz}$ ) and the output current were recorded at different frequencies $(f)$. A continuous bias was also added to reproduce the gate bias effect present in the OFET devices. The phase angle $\theta$, defined by: 
$\theta=\arctan (-2 \pi f * C / G)$

where $\mathrm{C}$ is the capacitance and $\mathrm{G}$ the conductance, allows to discriminate among different relaxation phenomena as well as to ascribe dominant capacitive or conductive behaviors at specific frequency ranges. Notably, $-90^{\circ}<\theta<-45^{\circ}$ is indicative of a dominant capacitive behavior while for $-45^{\circ}<\theta<0^{\circ}$ the system is predominantly conductive.

In Figs. $2 \mathrm{~B}$ and $2 \mathrm{C}$ the $\theta$ vs. $f$ is plotted at $\mathrm{V}_{\mathrm{DC}}=0 \mathrm{~V}$ and $\mathrm{V}_{\mathrm{DC}}=-0.6 \mathrm{~V}$ for the two elicited systems. An overall conductive behavior is seen at high frequency (HF, f $>100 \mathrm{~Hz})$. However, the PL including structure, displays $\theta$ values closer to $-45^{\circ}$, and is thus slightly less conductive. This HF component is attributed to the migration of $\mathrm{OH}^{-}$and $\mathrm{H}^{+}$ions, present at a concentration of $10^{-7} \mathrm{M}$ in pure water. $\theta$ changes with $\mathrm{V}_{\mathrm{DC}}$ at $\mathrm{HF}$, which mostly occur in the PL-OFET, are attributed to an ionic flow through the not completely dense PL film. Interestingly, in the low frequency (LF) regime, both systems display a dominant capacitive behavior, indicating the building up of a Helmholtz double layer at both the $\mathrm{P} 3 \mathrm{HT} / \mathrm{H}_{2} \mathrm{O}$ and $\mathrm{P} 3 \mathrm{HT} / \mathrm{PL} / \mathrm{H}_{2} \mathrm{O}$ interfaces [10]. In this range of frequency, the $\theta$ dependence on $\mathrm{V}_{\mathrm{DC}}$ can be attributed to the onset of water electrolysis [14]. The capacitance of $0.9 \mu \mathrm{F}^{*} \mathrm{~cm}^{-2}$ for the $\mathrm{Au} / \mathrm{P} 3 \mathrm{HT} / \mathrm{H}_{2} \mathrm{O} / \mathrm{Au}$ system and $0.7 \mu \mathrm{F}^{*} \mathrm{~cm}^{-2}$ for the PL-OFET, respectively, leads to mobility values of $(4.6 \pm 0.3) * 10^{-3} \mathrm{~cm}^{2} \mathrm{~V}^{-1} \mathrm{~s}^{-1}$ and $(1.5 \pm 0.1)^{*} 10^{-3} \mathrm{~cm}^{2} \mathrm{~V}^{-1} \mathrm{~s}^{-1}$, in line with previous determinations [14].

To identify the contribution of each component of the OFET (PL film, water and OS), the impedance data were fitted to equivalent circuits [20] comprising ideal capacitor (C) and resistor (R) elements along with constant phase elements (CPE) accounting for inhomogeneity. The CPE impedance is defined by:

$Z_{C P E}=K^{-1}(j \omega)^{-\alpha}$ 
If $\alpha=1$, then $K=C$ and the $Z_{C P E}$ turns into an ideal capacitor. When $\alpha=0, K^{-1}=R$ i.e. $Z_{C P E}$ stands for an ideal resistance [21]. A CPE is a hybrid element already proposed to model non ideal behaviors in OS and PL layers [21-23]. The fitted curves are reported for the spectra measured at $\mathrm{V}_{\mathrm{DC}}=-0.6 \mathrm{~V}$ as continuous red lines while all the fitting parameters are reported in Table $1 \mathrm{~S}$ and $2 \mathrm{~S}$.

The equivalent circuit for the $\mathrm{Au} / \mathrm{P} 3 \mathrm{HT} / \mathrm{H}_{2} \mathrm{O} / \mathrm{Au}$ system is given in the inset of Fig. $2 \mathrm{C}$ along with a schematic representation of the interfaces modelled by a single circuital element or by a combination of them. Three different contributions can be identified for the curve at $\mathrm{V}_{\mathrm{DC}}=-$ $0.6 \mathrm{~V}$ : the first $\left(\mathrm{C}_{\mathrm{DL} 1}\right)$ and the third $\left(\mathrm{CPE}_{\mathrm{DL} 2}\right.$ and $\left.\mathrm{R}_{\mathrm{DL} 2}\right)$ ones, characterized by a capacitance in the $\mu \mathrm{F}^{*} \mathrm{~cm}^{-2}$ range, represent the Helmholtz double layers at the $\mathrm{Au} / \mathrm{H}_{2} \mathrm{O}$ and $\mathrm{P} 3 \mathrm{HT} / \mathrm{H}_{2} \mathrm{O}$ interfaces respectively and contribute to the $L F$ part of the spectrum. $R_{D L 1}$ (i.e. the $C_{D L 1}$ parallel resistance) was neglected because of its very high value. The middle component $\left(\mathrm{C}_{\mathrm{H} 2 \mathrm{O}}=1.7 * 10^{-10} \mathrm{~F}^{*} \mathrm{~cm}^{-2}\right.$ and $\left.\mathrm{R}_{\mathrm{H} 2 \mathrm{O}}=1.1 * 10^{+5} \Omega\right)$ accounts for a $\mathrm{HF}$ contribution coming from the polarization of the gating water. The spectrum at $\mathrm{V}_{\mathrm{DC}}=0 \mathrm{~V}$ was modeled by a similar circuit with fitting parameters of the same order of magnitude. In this case, a single capacitor $\left(\mathrm{K}_{\mathrm{DL}}=1.1 * 10^{-6} \Omega^{-1} *(\mathrm{rad} / \mathrm{sec})^{-\alpha} / \mathrm{cm}^{2}, \alpha=1.0\right)$ is used to account for a series of not distinguishable contributions coming from double layers forming at the $\mathrm{Au} / \mathrm{H}_{2} \mathrm{O}$ and $\mathrm{P} 3 \mathrm{HT} / \mathrm{H}_{2} \mathrm{O}$ interfaces (see supplementary information).

The equivalent circuit at $\mathrm{V}_{\mathrm{DC}}=-0.6 \mathrm{~V}$ for the PL-OFET is reported in Fig. 2D along with a schematic representation of the phenomena associated to each interface. The model comprises two sets of circuital elements. The first one $\left(C_{\mathrm{DL} 1}=5.0 * 10^{-6} \mathrm{~F}^{*} \mathrm{~cm}^{-2}\right.$ and $\left.\mathrm{R}_{\mathrm{DL} 1}=1.2 * 10^{+7} \Omega\right)$ describes the double layer at the $\mathrm{Au} / \mathrm{H}_{2} \mathrm{O}$ interface. The set of elements modeling the PL layer and interfaces needs to take into account its complex structure, which comprises an ordered and compact part (mainly involving PL molecules organized in a layer structure) and a more 
disordered region including vesicles that are formed by the dissolution of the PL film while in contact with the gating water (see sketches in Table $2 \mathrm{~S}$ ). $\mathrm{CPE}_{\mathrm{PLves}}$ is associated to the latter component [24] and the output $\alpha$ value of 0.3 accounts for the dielectric relaxation times dispersion associated with the presence of the vesicle size distribution [23]. Conversely, $\mathrm{C}_{\mathrm{DL} 3}=4.6^{*} 10^{-6} \mathrm{~F}^{*} \mathrm{~cm}^{-2}$ as well as $\mathrm{C}_{\mathrm{PL}}=4.6^{*} 10^{-10} \mathrm{~F}^{*} \mathrm{~cm}^{-2}$ and $\mathrm{R}_{\mathrm{PL}}=1.3^{*} 10^{+4} \Omega$ model the ordered part of the PL layer. Based on both capacitance values, $\mathrm{C}_{\mathrm{DL} 3}$ is assigned to the $\mathrm{H}_{2} \mathrm{O} / \mathrm{PL}$ double layer while $\mathrm{C}_{\mathrm{PL}}$ is assigned to the dielectric properties of the PL film directly interfaced to the OS. Finally, $\mathrm{R}_{\mathrm{L}}\left(3.2^{*} 10^{+6} \Omega\right)$, quite a high value, accounts for the low leakage contribution affecting the overall PL film (including both the ordered and the more disordered regions). Although the model clearly predicts that partial PL dissolution occurs, evidence for an equilibrium involving the presence of a steady PL interface is found in the reproducible presence of $\mathrm{C}_{\mathrm{PL}}$ only in the PL-OFET devices.

The data relevant to the ionic gating solution are reported in Fig. 3. Panel (A) shows the transfer characteristics $\left(I_{D S}-V_{G}\right)$ measured at two different voltage sweep rates (red curve for $22 \mathrm{mV} \mathrm{s}^{-1}$ and black curve for $252 \mathrm{mV} \mathrm{s}^{-1}$ ) for a PL-OFET exposed to a $\mathrm{LiClO}_{4}$ solution at a physiological relevant concentration of $0.005 \mathrm{M}$. In this case, two quite different gate voltage sweeping rates were chosen because they have a noticeable effect on the hysteresis measured during the recording $[10,25]$, which can help to distinguish between charge transfer and capacitive gating effect [26]. The curves were measured with a gate bias ranging between 0.1 and $-0.5 \mathrm{~V}$ and at $\mathrm{V}_{\mathrm{DS}}=-0.5 \mathrm{~V}$. The arrows indicate the direction of the forward and backward sweeps. Fig. 3B shows the bare P3HT-OFET transfer-characteristics. The comparison between Fig. 3A and 3B brings evidence for that PL film improves the OFET performance, since the hysteresis loop area reduces and an on/off ratio of $10^{3}$ is measured (Table 1). The electronic performances of the bare P3HT-OFET degrade upon the direct exposure to the lithium perchlorate aqueous solution. This system shows a progressive current increase as the 
sweeping rate decreases, as well as a larger hysteresis area, which can be attributed to the penetration of perchlorate anions into the OS combined with other mechanisms [27]. Further investigation would be needed to determine the contribution of each phenomenon to the overall OFET hysteresis, which is outside the scope of this paper. It is important to note that, at variance to what observed for the bare P3HT-OFET, this sweeping rate dependence was not observed when the lipid film is interfaced to the OFET, thus indicating that the anion migration is minimized [10]. The hysteresis is almost identical to or slightly lower, at a slower sweeping rate, thus supporting the occurrence of a capacitive, rather than an electrochemical gating process [26]. The capacitance values used for estimating mobility estimation are of 3.3 $\mu \mathrm{F}^{*} \mathrm{~cm}^{-2}$ for the $\mathrm{Au} / \mathrm{P} 3 \mathrm{HT} / \mathrm{LiClO}_{4} / \mathrm{Au}$ system and $0.7 \mu \mathrm{F}^{*} \mathrm{~cm}^{-2}$ for the PL-OFET. Two different $\mu_{\mathrm{FET}}$ values were estimated for the bare OFET: at faster sweeping rate $\mu_{\mathrm{FET}}$ is of the order of $10^{-4} \mathrm{~cm}^{2} \mathrm{~V}^{-1} \mathrm{~s}^{-1}$, while at lower sweeping rate $\mu_{\mathrm{FET}}$ is in the $10^{-3} \mathrm{~cm}^{2} \mathrm{~V}^{-1} \mathrm{~s}^{-1}$ range. A mobility of $(6.4 \pm 0.7) * 10^{-3} \mathrm{~cm}^{2} \mathrm{~V}^{-1} \mathrm{~s}^{-1}$ was found for the PL-OFET.

The EIS results of both systems exposed to the perchlorate solution are reported in Figs. 3C and 3D. Error bars, taken as standard deviation over three replicates, are added to the PL including system data measured at $\mathrm{V}_{\mathrm{DC}}=-0.6$ Volt. For all the data sets, the relative standard deviation (RSD) ranges between $2 \%$ and $26 \%$ (at very high frequencies), thus showing a quite good reproducibility. A similar degree of reproducibility was seen also in the spectra recorded for the other systems. The two equivalent circuits used for the $\mathrm{LiClO}_{4}$ solution gated systems are similar to those discussed with pure water. Although in the system having the P3HT directly interfaced to a $\mathrm{LiClO}_{4}$ solution, the $\mathrm{C}_{\mathrm{DL} 1}$ element needs to be substituted by a CPE, the $\alpha_{D L 1}$ value, 0.9 , indicates that this element is almost an ideal capacitance. For the sake of conciseness, a detailed description of the features similar to those already addressed with the water-gated systems will not be given. Instead, all the best-fit parameters are reported in Tables $1 \mathrm{~S}$ and 2S. Only two features are further discussed here. The bare P3HT system exhibits a more capacitive behavior $\left(\mathrm{K}_{\mathrm{DL} 2}\right)$ along with a $\mathrm{R}_{\mathrm{DL} 2}$ more than two orders of 
magnitude lower, when $\mathrm{LiClO}_{4}$ is added to the gating-solution, thus confirming the occurrence of $\mathrm{ClO}_{4}{ }^{-}$ion penetration in the OS. Therefore, the comparison between the resistance values gives a quantitative evaluation of the electrochemical doping which could be quantified in a resistance reduction of a factor of $10^{+2}$. For PL-OFETs, in addition to the already described $\mathrm{CPE}_{\mathrm{PLves}}$ element accounting for the PL in-homogeneity, a constant phase element $\left(C P E_{L}\right)$, rather than a resistive leakage contribution $\left(R_{L}\right)$, is needed to account for the increased PL dielectric relaxation-time dispersion when the film is in contact with a gating solution of higher ionic concentration. This attribution is further supported by the increase of the relevant $\alpha_{\mathrm{L}}$ value, from 0.2 at $\mathrm{V}_{\mathrm{DC}}=0 \mathrm{~V}$ to 0.4 at $\mathrm{V}_{\mathrm{DC}}=-0.6 \mathrm{~V}$, thus accounting for the ionic drift increase [24]. Despite the introduction of an additional CPE element, a capacitive behavior is supported by the presence of the $\mathrm{C}_{\mathrm{PL}}$ element, being $2.8 * 10^{-7}$ Farad ${ }^{*} \mathrm{~cm}^{-2}$, corresponding to the ordered portion of the PL layer at the interface with P3HT. Besides, this capacitance increases with $\mathrm{V}_{\mathrm{DC}}$, giving further support for that the PL layer acts as a barrier to ion penetration into the organic semiconductor.

\section{Conclusion}

In conclusion we describe an electrolyte-gated OFET including a zwitterionic PL film at the interface between the OS and the ionic-gating solution. The PL layer is shown to efficiently act as a barrier against ion diffusion into the OS, thus allowing the PL-OFET devices to operate mostly in a capacitive mode when gated by a solution with physiologically relevant salt concentration. The OFETs show good electrical performance with a field-effect mobility of $6.410^{-3} \mathrm{~cm}^{2} \mathrm{~V}^{-1} \mathrm{~s}^{-1}$ and an on/off ratio of $10^{3}$. These results represent a significant step towards the development of FET biosensors potentially capable to operate in direct contact with physiological fluids. Besides, it constitutes an essential basis for further developments involving the integration of receptors and proteins in general, into a PL layer while the PL film longer - term stability will be faced by covalently attaching the layer to an OS bearing 
carboxyl anchoring groups at the surface. These aspects are currently under investigation and will be addressed in the future.

\section{Acknowledgements}

The research leading to these results has received funding from the European Union Seventh Framework Programme ([FP7/2007-2013] under grant agreement $n^{\circ} 248728$. 


\section{References}

[1] E.T. Castellana, P.S. Cremer, Solid supported lipid bilayers: From biophysical studies to sensor design, Surf. Sci. Rep. 61 (2006) 429-444.

[2] P.K. Ang, M. Jaiswal, C.H.Y.X. Lim, Y. Wang, J. Sankaran, A. Li, C.T. Lim, T.

Wohland, O. Barbaros, K.P. Loh, A Bioelectronic Platform Using a Graphene Lipid Bilayer Interface, ACS Nano 4 (2010) 7387-7394

[3] N. Misra, J.A. Martinez, S.C.J. Huang, Y.M. Wang, P. Stroeve, C.P. Grigoropoulos, A. Noy, Bioelectronic silicon nanowire devices using functional membrane proteins, Proc. Natl Acad. Sci.USA106 (2009) 13780-13784.

[4] X.J. Zhou, J.M. Moran-Mirabal, H.G. Craighead, P.L. McEuen, Supported lipid bilayer/carbon nanotube hybrids, Nat. Nanotechnol. 2 (2007) 185-190.

[5] L. Torsi, A. Dodabalapur, Organic Thin-Film Transistors as Plastic Analytical Sensors, Anal. Chem. 77 (2005) 380A-387A.

[6] L. Torsi, G.M. Farinola, F. Marinelli, M.C. Tanese, O. Hassan Omar, L. Valli, F. Babudri, F. Palmisano, P.G. Zambonin, F. Naso, A sensitivity-enhanced field-effect chiral sensor, Nat. Mater. 7 (2008) 412-417.

[7] D.A. Bernards, G.G. Malliaras, Steady-state and transient behavior of organic electrochemical transistors, Adv. Funct. Mater. 17 (2007) 3538-3544.

[8] D.A. Bernards, G.G. Malliaras, G.E.S. Toombes, S.M. Gruner, Gating of an organic transistor through a bilayer lipid membrane with ion channels, Appl. Phys. Lett. 89 (2006) 053505-053505-3.

[9] R.M. Owens, G.G. Malliaras, Organic Electronics at the Interface with Biology, MRS bulletin 35 (2010) 449-456.

[10] L. Herlogsson, X. Crispin, N.D. Robinson, M. Sandberg, O.J. Hagel, G. Gustafsson, M. Berggren, Low-voltage polymer field-effect transistors gated via a proton conductor, Adv. Mater. 19 (2007) 97-101.

[11] I.N. Hulea, H.B. Brom, A. J. Houtepen, D. Vanmaekelbergh, J.J. Kelly, E.A. Meulenkamp, Wide Energy-Window View on the Density of States and Hole Mobility in Poly(p-PhenyleneVinylene), Phys. Rev. Lett. 93 (2004) 166601 (4 pp.).

[12] E. Bard, L. Faulkner, Electrochemical Methods: Fundamentals and Applications, second ed., Wiley, New York, 2001.

[13] S. Mitra, A. K. Shukla, S. Sampath, Electrochemical capacitors with plasticized gelpolymer electrolytes, J. Power Sources 101 (2001) 213-218.

[14] L. Kergoat, L. Herlogsson, D. Braga, B. Piro, M.-C. Pham, X. Crispin, M. Berggren, G. Horowitz, A Water-Gate Organic Field-Effect Transistor, Adv. Mater. 22 (2010) 2565-2569. [15] L. Kergoat, N. Battaglini, L. Miozzo, B. Piro, M.C. Pham, A. Yassar, G. Horowitz, Use of poly(3-hexylthiophene)/poly(methyl methacrylate) (P3HT/PMMA) blends to improve the performance of water-gated organic field-effect transistors, Org. Electron. 12 (2011) 12531257.

[16] M. Grit, D.J. Crommelin, Chemical stability of liposomes: implications for their physical stability, Chem. Phys. Lipids 64 (1993) 3-18.

[17] M. Urien, G. Wantz, E. Cloutet, L. Hirsch, P. Tardy, L. Vignau, H. Cramail, J.P. Parnei, Field-effect transistors based on poly(3-hexylthiophene): Effect of impurities, Org. Electron. 8 (2007) 727-734.

[18] D. Braga, G. Horowitz, High-Performance Organic Field-Effect Transistors, Adv. Mater. 21 (2009) 1473-1486.

[19] R.P. Richter, J. Lai Kee Him, L. Tessier, C. Tessier, A.R. Brisson, Supported Lipid

Membranes, Mater. Today 6 (2003) 32-37.

[20] A software can be downloaded free of charge from EISSA

http://www.abc.chemistry.bsu.by/vi/analyser/ (last accessed October $14^{\text {th }}, 2011$ ) 
[21] H. Hillebrandt, G. Wiegand, M. Tanaka, E. Sackmann, High Electric Resistance Polymer/Lipid Composite Films on Indium-Tin-Oxide (ITO) Electrodes, Langmuir 15 (1999) 8451-8459.

[22] Y. Shao, Y. Jin, J. Wang, L. Wang, F. Zhao, S. Dong, Conducting polymer polypyrrole supported bilayer lipid membranes, BiosensBioelectron20 (2005) 1373-1379.

[23] E. Barsoukov, J. R. Macdonald, Impedance Spectroscopy Theory, Experiment, and Applications, second ed., Wiley, New York, 2005.

[24] O. Larsson, E. Said, M. Berggren, X. Crispin, Insulator Polarization Mechanisms in Polyelectrolyte-Gated Organic Field-Effect Transistors, Adv. Funct. Mater. 19 (2009) 33343341.

[25] M.J. Panzer, C.R. Newman, C.D. Frisbie, Low-voltage operation of a pentacene fieldeffect transistor with a polymer electrolyte gate dielectric, Appl. Phys. Lett.86 (2005) 103503103503-3

[26] H. Wang, Y. Wu, C. Cong, J. Shang, T. Yu, Hysteresis of Electronic Transport in Graphene Transistors, ACS Nano 4 (2010) 7221-7228.

[27] M. Egginger, S. Bauer, R. Schwödiauer, H. Neugebauer, N.S. Sariciftci, Current versus gate voltage hysteresis in organic field effect transistors, Monatsh. Chem. 140 (2009) 735750 . 
Fig. 1. Structure of the solution-gated PL-OFET along with the chemical structures of the P3HT organic semiconductor and phosphatidylcholine PL molecule.

Fig. 2. (A) $\mathrm{I}_{\mathrm{DS}} v s$. $\mathrm{V}_{\mathrm{DS}}$ curves of a water-gated PL-OFET. Gate biases $\left(\mathrm{V}_{\mathrm{G}}\right)$ range from $0.1 \mathrm{~V}$ to $-0.5 \mathrm{~V}$ in steps of $-0.1 \mathrm{~V}$. (B) Impedance phase angle spectra of the water-gated PL-OFET obtained by applying a sine-wave $\mathrm{V}_{\mathrm{AC}}$ signal of $50 \mathrm{mV}$ and a direct bias $\mathrm{V}_{\mathrm{DC}}=0 \mathrm{~V}(\rightarrow-)$ ) or $\mathrm{V}_{\mathrm{DC}}=-0.6 \mathrm{~V}(\triangle-)$. The latter data are presented along with the best-fit curve (red solid line) associated to the equivalent circuit reported in panel (D) together with a scheme-of the phenomena associated to each interfaces. (C) Same as (B) for a water-gated OFET

Fig. 3. (A) $\mathrm{I}_{\mathrm{DS}} v s$. $\mathrm{V}_{\mathrm{G}}$ transfer characteristics of a $\mathrm{LiClO}_{4}$ solution-gated PL-OFET and (B) bare OFET at a voltage sweep rate of $252 \mathrm{mV} \mathrm{s}^{-1}$ (black curve) and $22 \mathrm{mV} \mathrm{s}^{-1}$ (red curve). The arrows indicate the direction of the forward and backwards potential sweeps. (C) Impedance phase angle spectra obtained applying a sine-wave $\mathrm{V}_{\mathrm{AC}}$ signal of $50 \mathrm{mV}$ and a direct bias $\mathrm{V}_{\mathrm{DC}}=0 \mathrm{~V}(\longrightarrow-)$ and $\mathrm{V}_{\mathrm{DC}}=-0.6 \mathrm{~V}(-\backsim)$ for the Au/P3HT/PL-film/LiClO $/ 4 / \mathrm{Au}$ system and for the $\mathrm{Au} / \mathrm{P} 3 \mathrm{HT} / \mathrm{LiClO}_{4} / \mathrm{Au}(\mathrm{D})$ along with the best fitting curve taken at $\mathrm{V}_{\mathrm{DC}}=-$ $0.6 \mathrm{~V}$ (red solid line) resulting from the equivalent circuits reported as insets. Error bars, taken as standard deviation over three replicates, are added to the phase angle data at $\mathrm{V}_{\mathrm{DC}}=-0.6 \mathrm{~V}$ in panel (C).

Table 1. Field-effect mobility, threshold voltage and on/off ratio extracted from the transfer characteristics in the saturation regime as average values on eight measurements for water or $\mathrm{LiClO}_{4}$ solution - gated PL-OFET and bare OFET. The standard deviation (SD) is given as associated error. In the case of $\mathrm{LiClO}_{4}$ solution-gated OFET the figures of merit were estimated at sweeping rate potential of $252 \mathrm{mV} \mathrm{s}^{-1}$ (a) and $22 \mathrm{mVs}^{-1}$ (b).

\begin{tabular}{|c|c|c|c|c|c|c|}
\hline & \multicolumn{3}{|c|}{ PL-OFET } & \multicolumn{3}{|c|}{ OFET } \\
\hline & {$\left[\mathrm{cm}^{\left.\frac{\mu_{\mathrm{FET}}}{\mathrm{F}^{-1}} \mathrm{~s}^{-1}\right]}\right.$} & $\begin{array}{c}V_{T} \\
{[V]} \\
\end{array}$ & Ion/off & {$\left[\mathrm{cm}^{\frac{\mu_{\text {FET }}}{\mathrm{v}^{-1}}} \mathrm{~s}^{-1}\right]$} & $\begin{array}{l}V_{T} \\
{[V]} \\
\end{array}$ & Ion/off \\
\hline \multicolumn{7}{|c|}{ pure aqueous solution } \\
\hline average value \pm SD & $(1.5 \pm 0.1)^{*} 10^{-3}$ & $-0.04 \pm 0.01$ & $318 \pm 168$ & $(4.6 \pm 0.3)^{*} 10^{-3}$ & $-0.07 \pm 0.02$ & $739 \pm 71$ \\
\hline \multicolumn{7}{|c|}{ aqueous lithium perchlorate solution $(0.005 \mathrm{M})$} \\
\hline average value \pm SD & $(6.4 \pm 0.7)^{*} 10^{-3}$ & $-0.05 \pm 0.02$ & $1135 \pm 333$ & $\begin{array}{l}{ }^{a}(4.2 \pm 5.2)^{*} 10^{-4} \\
b(5.3 \pm 0.3)^{*} 10^{-3}\end{array}$ & $\begin{array}{c}\mathrm{a}-0.03 \pm 0.09 \\
-\end{array}$ & $\begin{array}{c}{ }^{\mathrm{a}} 72 \pm 48 \\
{ }^{\mathrm{b}} 313 \pm 178\end{array}$ \\
\hline
\end{tabular}




\section{Supplementary Information}

Fig. 1SI. SAXS curve of PL vesicles spin coated on kapton film. It is evident the lamellar periodicity (Bragg's peaks up to the fourth order are discernible). The repeat distance $d$ extracted from the position of the first-order peak is $5 \mathrm{~nm}$, that is, twice the size of a phospholipid molecule, thus demonstrating that the bilayer is the repeated structure.

Fig. 2SI. (A) I $\mathrm{I}_{\mathrm{DS}} v s . \mathrm{V}_{\mathrm{G}}$ transfer characteristics of a water-gated PL-OFET and (B) bare OFET at a voltage sweep rate of $252 \mathrm{mV} \mathrm{s}^{-1}$ (black curve) and $22 \mathrm{mV} \mathrm{s}^{-1}$ (red curve). The arrows indicate the direction of the forward and backwards potential sweeps.

Table 1S. Best-fit parameters for the $\mathrm{Au} / \mathrm{P} 3 \mathrm{HT} / \mathrm{H}_{2} \mathrm{O}$ or $\mathrm{LiClO}_{4} / \mathrm{Au}$ systems at $\mathrm{V}_{\mathrm{DC}}=0 \mathrm{~V}$ and $\mathrm{V}_{\mathrm{DC}}=-0.6 \mathrm{~V}$.

Table 2S. Best-fit parameters for the $\mathrm{Au} / \mathrm{P} 3 \mathrm{HT} / \mathrm{PL}$ film $/ \mathrm{H}_{2} \mathrm{O}$ or $\mathrm{LiClO}_{4} / \mathrm{Au}$ systems at $\mathrm{V}_{\mathrm{DC}}=0 \mathrm{~V}$ and $\mathrm{V}_{\mathrm{DC}}=-0.6 \mathrm{~V}$.

Fig. 3SI. Equivalent circuits for the $\mathrm{Au} / \mathrm{P} 3 \mathrm{HT} / \mathrm{H}_{2} \mathrm{O} / \mathrm{Au}$ system $(\mathrm{A})$, for the $\mathrm{Au} / \mathrm{P} 3 \mathrm{HT} / \mathrm{LiClO}_{4} / \mathrm{Au}(\mathrm{B})$, for the Au/P3HT/PL film/ $\mathrm{H}_{2} \mathrm{O} / \mathrm{Au}$ system (C) and for the $\mathrm{Au} / \mathrm{P} 3 \mathrm{HT} / \mathrm{PL}$ film/LiClO$/ 4 \mathrm{Au}$ (D) along with a schematic representation of the phenomena associated to each interface. 